\title{
Erratum to: Women with one ovary in assisted reproduction technologies: a review of the literature
}

Sofia Bouchlariotou - Panagiotis Tsikouras •

Beniamin Rösing · Josef Neulen

Published online: 27 September 2012

(C) Springer-Verlag Berlin Heidelberg 2012

Erratum to: Arch Gynecol Obstet (2012)

286:1041-1047

DOI 10.1007/s00404-012-2477-1

Unfortunately, the first and surnames of the complete author group has been swapped in the online publication of the article. The correct listing of the author group is given below.

Sofia Bouchlariotou · Panagiotis Tsikouras .

Beniamin Rösing · Josef Neulen

The online version of the original article can be found under doi:10.1007/s00404-012-2477-1.

S. Bouchlariotou $\cdot$ B. Rösing $\cdot$ J. Neulen

Laboratory of Reproductive Physiology, University of Aachen,

Aachen, Germany

P. Tsikouras $(\bowtie)$

Department of Obstetrics and Gynecology, Democritus

University of Thrace, Alexandroupolis, Greece

e-mail: ptsikour@med.duth.gr 